\title{
PENGARUH MEDIA BERBASIS VIDEO TERHADAP PENGETAHUAN IBU AKSEPTOR KB TENTANG PENTINGNYA KB DI WILAYAH KERJA PUSKESMAS PATTINGALLOANG
}

\author{
Aldila Febriani Ngangun ${ }^{1}$, Susi Sastika Sumi ${ }^{2}$, Simunati $^{3}$ \\ ${ }^{1}$ STIKES Nani Hasanuddin Makassar \\ ${ }^{2}$ STIKES Nani Hasanuddin Makassar \\ ${ }^{3}$ Kemenkes Poltekes Makassar
}

Alamat Korespondensi : (aldilafebriani.n@gmail.com/089664771397)

\begin{abstract}
ABSTRAK
Pengetahuan yang rendah dan persepsi yang salah tentang keluarga berencana dan alat kontrasepsi menyebabkan wanita takut menggunakan alat kontrasepsi. Hal ini merupakan salah satu indikator Tingginya angka kematian ibu, terutama di negara-negara dengan tingkat pertumbuhan populasi yang tinggi namun dengan prevalensi kontrasepsi yang rendah. Pemberian Media berbasis video sebagai salah satu media audiovisual dapat membantu sebagai salah satu cara untuk menyampaikan informasi yg efektif untuk meningkatkan pengetahuan masyarakat. Tujuan penelitian ini yaitu untuk diketahuinya pengaruh media berbasis video terhadap pengetahuan ibu akseptor KB tentang pentingnya KB di wilayah kerja puskesmas Pattingalloang. Penelitian ini menggunakan jenis penelitian kuantitatif dengan metode penelitian Experimental design yaitu pra-experimental dengan pendekatan rancangan One-group pretest-posttest design. Pengambilan sampel menggunakan teknik non-probability sampling yaitu purposive sampling. Pengumpulan data dilakukan dengan menggunakan kuesioner dan dianalisis dengan melakukan uji statistik non-parametrik yaitu uji Wilcoxon Signed-Rank Test. Hasil penelitian didapatkan nilai $\rho=0,001<\alpha=0,05$, yang berarti $H_{a}$ diterima yang artinya ada pengaruh media berbasis video terhadap pengetahuan ibu akseptor $\mathrm{KB}$ tentang pentingnya KB. Kesimpulan dalam penelitian ini adalah ada pengaruh setelah pemberian media berbasis video terhadap pengetahuan ibu akseptor KB tentang pentingnya KB Di Wilayah Kerja Puskesmas Pattingalloang.
\end{abstract}

Kata Kunci : Keluarga Berencana, Media Berbasis Video, Pengetahuan

\section{PENDAHULUAN}

Menurut World Health Organization (WHO), 2018 penggunaan kontrasepsi telah meningkat di banyak bagian dunia, terutama di Asia dan Amerika Latin, tetapi terus rendah di Afrika sub-Sahara. Secara global, penggunaan kontrasepsi modern sedikit meningkat, dari 54\% pada tahun 1990 menjadi $57,4 \%$ pada tahun 2015. Secara regional, proporsi wanita berusia 15-49 tahun yang melaporkan penggunaan metode kontrasepsi modern telah meningkat secara minimal atau meningkat antara 2008 dan 2015. Di Afrika naik dari $23,6 \%$ menjadi $28,5 \%$, di Asia naik sedikit dari $60,9 \%$ menjadi $61,8 \%$, dan di Amerika Latin dan Karibia tetap stabil di $66,7 \%$. Ada 214 juta wanita usia reproduksi di negara berkembang yang ingin menghindari kehamilan tidak menggunakan metode kontrasepsi modern. Alasan untuk ini termasuk pilihan metode yang terbatas, ketakutan atau pengalaman efek samping, dan buruknya kualitas layanan yang tersedia. Kebutuhan kontrasepsi yang tidak terpenuhi tetap terlalu tinggi. Ketidakadilan ini didorong oleh meningkatnya populasi.

Undang-Undang Nomor 52 tahun 2009 tentang perkembangan kependudukan dan pembangunan keluarga menyatakan bahwa pembangunan keluarga adalah upaya mewujutkan keluarga yang berkualitas yang hidup dalam lingkungan yang sehat dan keluarga berencana adalah upaya mengatur kelahiran anak, jarak dan usia ideal melahirkan, mengatur kehamilan melalui promosi, perlindungan, dan membantu sesuai hak reproduksi untuk mewujutkan keluarga berkualitas. Undang-undang ini mendukung program KB sebagai salah satu upaya untuk mewujudkan keluarga sehat dan berkualitas. Pengaturan kehamilan dalam program KB dilakukan dengan menggunakan alat kontrasepsi (Kemenkes RI, 2014).

Persentase peserta KB aktif terhadap pasangan usia subur di Indonesia pada tahun 2016 sebesar $74,8 \%$. Dari 33 provinsi, ada 15 provinsi yang presentasenya masih berada di bawah presentase nasional. Tiga provinsi yang memiliki persentase tertinggi yaitu 
Maluku Utara sebesar 87,03\%, Kepulauan Bangka Belitung sebesar 83,92\%, dan Sulawesi Utara sebesar $83,84 \%$, sedangkan presentase terendah terdapat di Provinsi Nusa Tenggara Timur sebesar $63,24 \%$, Sumatera Barat sebesar 63,73\%, dan DKI Jakarta sebesar $67,46 \%$. Provinsi Sulawesi Selatan merupakan salah satu provinsi dari 15 provinsi yang presentasenya masih berada di bawah presentase nasional yaitu sebesar $72,30 \%$ (Kemenkes RI, 2017).

Berdasarkan data awal yang didapatkan dari puskesmas Pattingalloang, pada tahun 2016 akseptor ibu KB di wilayah kerja puskesmas Pattingalloang sebanyak 488 ibu akseptor KB, pada tahun 2017 mengalami peningkatan yaitu 877 ibu akseptor KB, sedangkan tahun 2018 mengalami penurunan yaitu 762 ibu akseptor KB.

\section{BAHAN DAN METODE}

Lokasi, populasi, dan sampel.

Penelitian ini dilaksanakan di Wilayah Kerja Puskesmas Pattingalloang. Jumlah Populasi dalam penelitian 128, Sampel dalam penelitian ini sebanyak 56 .

1. Kriteria Inklusi
a. Ibu akseptor KB yang bersedia menjadi responden selama proses penelitian
b. Ibu akseptor KB berumur 15-49 tahun
c. Ibu akseptor KB yang kooperatif

2. Kriteria Eksklusi

a. Ibu akseptor KB yang hadir namun tidak bersedia untuk di teliti

b. Ibu akseptor KB yang mengalami gangguan fisik dan kecacatan mental (depresi, tuna netra, tuna rungu, tuna wicara)

\section{Pengumpulan Data}

1. Data Primer

Data primer yang di gunakan dalam penelitian ini di peroleh melalui pembagian kuesioner yang terdiri dari beberapa pertanyaan dengan menggunakan skala.

2. Data Sekunder

Data sekunder dalam penelitian ini adalah data sekunder yang diperoleh dan dikumpulkan oleh peneliti dari Wilayah Kerja Puskesmas Pattingalloang.

\section{Pengelolahan Data}

1. Editing

Editing adalah upaya untuk memeriksa kembali kebenaran data yang diperoleh atau dikumpulkan.

2. Coding

Coding merupakan kegiatan pemberian kode numerik (angka) terhadap data yang terdiri atas kategori.

\section{Data entry}

Data entry adalah kegiatan memasukkan data yang telah dikumpulkan kedalam master tabel atau atau data base komputer, kemudian membuat distribusi (frekuensi sederhana atau bisa juga dengan membuat tabel kontigensi (Hidayat, 2014).

\section{Analisis Data}

1. Analisis Univariat

Analisis univariat dilakukan pada setiap variable dari hasil penelitian untuk melihat distribusi frekuensi dan persentase masingmasing variable.

2. Analisis Bivariat

Analisis bivariat merupakan analisis yang dilakukan untuk melihat pengaruh antara variabel independen (media berbasis video) terhadap variabel dependen (pengetahuan ibu) dengan ketentuan nilai $p$ $<\alpha(0,05)$.

\section{HASIL}

1. Analisis univariat

Tabel 1 Distribusi Karakteristik Responden Di Wilayah Kerja Puskesmas Pattingalloang. $(n=56)$

\begin{tabular}{|c|c|c|c|}
\hline Karakteristik & $\mathrm{n}$ & $\%$ & Total \\
\hline Umur & & & \\
17-25 Tahun & 8 & 14,3 & \\
26-35 Tahun & 18 & 32,1 & 56 \\
36-45 Tahun & 23 & 41,1 & \\
46-55 Tahun & 7 & 12,5 & \\
\hline Pendidikan Terakhir & & & \\
SD & 22 & 39,3 & \\
SMP & 13 & 23,2 & 56 \\
SMA/SMK/Sederajat & 20 & 35,7 & \\
Sarjana (S1/S2/S3) & 1 & 1,8 & \\
\hline Pekerjaan & & & \\
Guru & 1 & 1,8 & 56 \\
IRT & 52 & 92,9 & \\
Lain-lain & 3 & 5,4 & \\
\hline
\end{tabular}

Berdasarkan tabel 1, menunjukkan bahwa dari 56 responden yang diteliti, diketahui bahwa kelompok umur responden paling banyak adalah kelompok umur 36-45 tahun dengan jumlah responden sebanyak 23 responden $(41,1 \%)$, dan responden paling sedikit adalah kelompok umur 46-55 tahun adalah sebanyak 7 responden (12,5\%). pendidikan ibu akseptor KB yang menjadi responden terdapat 22 responden $(39,3 \%)$ dan 1 responden $(1,8 \%)$ yang berpendidikan Sarjana (S1/S2/S3). lbu akseptor KB dengan pekerjaan paling banyak adalah IRT yaitu sebanyak 52 responden $(92,9 \%)$, Lain-lain sebanyak 3 responden $(5,4 \%)$, dan guru sebanyak 1 responden $(1,8 \%)$. 
2. Analisis Bivariat

Tabel 2 Analisis Pengaruh Media Berbasis Video Terhadap Pengetahuan Ibu Akseptor KB Tentang Pentingnya KB Di Wilayah Kerja Puskesmas Pattingalloang

\begin{tabular}{|c|c|c|c|c|c|}
\hline \multirow{3}{*}{$\begin{array}{l}\text { Kelompok } \\
\text { Perlakuan } \\
\text { (Intervensi) }\end{array}$} & \multicolumn{4}{|c|}{ Pengetahuan Ibu } & \multirow{3}{*}{ Mean } \\
\hline & \multicolumn{2}{|c|}{$\begin{array}{c}\text { Kurang } \\
\text { Tahu }\end{array}$} & \multicolumn{2}{|c|}{$\begin{array}{c}\text { Cukup } \\
\text { Tahu }\end{array}$} & \\
\hline & (n) & (\%) & $(n)$ & $(\%)$ & \\
\hline Pre Test & 15 & $\begin{array}{c}26 \\
8\end{array}$ & 41 & 73,2 & $\begin{array}{l}22, \\
91\end{array}$ \\
\hline Post T & 0 & 0 & 56 & 100 & $\begin{array}{c}27, \\
96\end{array}$ \\
\hline \multicolumn{6}{|c|}{$p=0,001$} \\
\hline
\end{tabular}

Berdasarkan tabel 2, menunjukkan bahwa dari 56 responden yang diteliti, diperoleh nilai rata-rata pengetahuan pre test ibu akseptor KB adalah 22,91, sedangkan nilai rata-rata pengetahuan post test ibu akseptor KB adalah 27,91. Ibu akseptor KB dengan pengetahuan cukup tahu sebelum diberikan media berbasis video adalah sebanyak 41 responden $(73,2 \%)$ dan pengetahuan kurang tahu berjumlah 15 responden $(26,8 \%)$, sedangkan ibu akseptor KB dengan pengetahuan cukup tahu setelah diberikan media berbasis video sebanyak 56 responden $(100 \%)$. Setelah dilakukan uji Wilcoxon Signed-Rank Test didapatkan nilai $\rho(0,001)$ yang berarti nilai $\rho<\alpha$ $(0,05)$, maka $H_{a}$ diterima yang artinya ada perbedaan nilai pre test dan post test Pengetahuan Ibu Akseptor KB Di Wilayah Kerja Puskesmas Pattingalloang sebelum dan sesudah diberikan Media Berbasis Video tentang pentingnya KB.

\section{PEMBAHASAN}

1. Karakteristik Umum Responden

Berdasarkan hasil penelitian menurut karakteristik responden didapatkan jumlah kelompok umur responden paling banyak adalah kelompok umur 36-45 tahun dan 26-35 tahun sebagai kelompok umur terbanyak kedua. Umur responden termasuk masa produktif dan resiko tinggi kehamilan serta kelahiran sehingga berpotensi besar untuk hamil kembali, hal ini sesuai dengan teori Koes Irianto (2014) yang menjelaskan umur ideal menjadi hamil antara 24-35 tahun. Kurang atau lebih dari umur ideal itu, ada risiko dalam kehamilan salah satunya adalah kematian ibu. Kehamilan di atas 35 tahun tergolong berisiko tinggi, sehingga pasangan usia subur (PUS) diharapkan untuk mengakhiri kehamilannya.

Hasil penelitian Nomleni (2014) menjelaskan sebagian besar responden adalah ibu yang berumur risiko dalam penelitian tentang faktor yang berhubungan dengan pemilihan alat kontrasepsi Intra Uterine Device (IUD) pada ibu post partum normal.

Hasil penelitian Farahan (2016) menjelaskan sebagian besar respoden adalah ibu yang berumur risiko rendah dalam penelitian tentang tingkat pengetahuan penggunaan alat kontrasepsi pada wanita usia subur.

Hasil penelitian tingkat pendidikan responden sebagian besar pada tingkat SD dan SMA. Pendidikan formal sangat besar pengaruhnya terhadap pengetahuan seseorang, bila seseorang berpendidikan tinggi maka akan memiliki pengetahuan yang tinggi pula sebaliknya jika seseorang memiliki pendidikan rendah akan memiliki pengetahuan yang rendah dan akan mempengaruhi dalam memahami sesuatu hal. Hal ini sesuai dengan teori Notoadmodjo (2003) dalam Titik Lestari (2015), yang mengemukakan bahwa semakin tinggi pendidikan seseorang maka akan mempengaruhi perilaku seseorang termasuk dalam pemilihan kontrasepsi.

Penelitian ini sejalan dengan yang dilakukan oleh Hidayatulloh (2017) menjelaskan bahwa tingkat pendidikan seseorang berpengaruh terhadap kemampuan seseorang tersebut untuk menerima dan memahami suatu pengetahuan yang didapatkan, termasuk menerima informasi dari pendidikan kesehatan tentang KB IUD.

Penelitian ini sejalan dengan yang dilakukan oleh Hasnaeni \& Mujriah (2018) menjelaskan bahwa jenis pekerjaan penggunaan alat kontrasepsi yang paling banyak adalah IRT. Penelitian ini juga sejalan dengan yang dilakukan oleh Nomleni (2014) menjelaskan bahwa jenis pekerjaan IRT merupakan pekerjaan terbanyak dalam pemilihan alat kontrasepsi Intra Uterine Device (IUD) pada ibu post partum.

Hasil penelitian menunjukkan bahwa dari 56 responden jumlah anak hidup paling banyak adalah 3 anak, kemudian terbanyak kedua yaitu 2 anak. Hal ini menunjukkan bahwa pengguna metode kontrasepsi mengalami peningkatan, dikarenakan banyaknya anak merupakan salah satu faktor pasangan suami istri tersebut memilih menggunakan alat kontrasepsi.

Penelitian ini sejalan dengan yang dilakukan oleh Rizali, dkk (2013) menyatakan ada hubungan antara jumlah 
anak hidup dengan pemilihan metode kontrasepsi suntik di Kelurahan Mattoangin Kecematan Mariso Kota Makassar.

2. Distribusi Frekuensi Responden Berdasarkan Pengetahuan Ibu Pre TestPost Test Ibu Akseptor KB

Berdasarkan hasil penelitian menunjukkan bahwa dari 56 responden yang diteliti berdasarkan pengetahuan pre test ibu akseptor KB sebelum diberikan media berbasis video terdapat 41 responden $(73,2 \%)$ yang berpengetahuan cukup tahu dan 15 responden $(26,8 \%)$ yang mempunyai pengetahuan kurang tahu tentang pentingnya $\mathrm{KB}$, sedangkan berdasarkan pengatahuan post test ibu akseptor KB setelah diberikan media berbasis video terdapat 56 responden $(100 \%)$ dengan kategori pengetahuan cukup tahu. Ditinjau dari nilai rata-rata pre test 22,91 dan nilai rata-rata post test 27,96, data ini menunjukkan bahwa pengetahuan ibu akseptor KB post test lebih tinggi dibandingkan pada hasil pengetahuan ibu akseptor KB pre test.

Hasil penelitian ini sejalan dengan penelitian yang dilakukan oleh Cynthia (2017) terdapat perbedaan tingkat pengetahuan ibu sebelum dan sesudah diberikan pendidikan kesehatan dengan nilai mean sebelum diberikan 61,4 \pm 12,0 dan sesudah diberikan menjadi 89,7 \pm 8,35 . Nilai $\rho$ value sebesar $0,000<\alpha=$ 0.05 , sehingga terdapat pengaruh pendidikan kesehatan melalui media video terhadap pengetahuan ibu primigravida tentang kontrasepsi IUD post plasenta di Puskesmas Piyungan.

Menurut asumsi peneliti bahwa penelitian ini menunjukkan pengetahuan ibu akseptor KB meningkat pada kemampuan kognitif $\mathrm{C} 1-\mathrm{C} 3$ yaitu mengetahui (knowing), memahami (comprehension), dan mengaplikasikan (application), dimana pada hasil post test didapatkan bahwa semua ibu akseptor KB berpengatahuan cukup tahu yang artinya ada perubahan pengetahuan setelah diberikan media berbasis video dan ibu akseptor mampu mengaplikasikan maksud dari pemberian media berbasis video tentang pentingnya KB dengan cara menjadi bagian dari akseptor KB yang aktif. Hasil penelitian ini sejalan dengan yang dilakukan oleh Cynthia (2017) yang menggambarkan bahwa penelitian dilakukan untuk mengetahui adanya perubahan pengetahuan ibu mengenai alat kontrasepsi IUD setelah diberikan pendidikan kesehatan menggunakan media video, dengan harapan semua ibu post plasenta setalah bersalin dapat menggunakan kontrasepsi IUD (C1-C3, mengetahui (knowing), memahami (comprehension), dan mengaplikasikan (application)).

3. Pengaruh Media Berbasis Video Terhadap Pengetahuan Ibu Akseptor KB Tentang Pentingnya KB Di Wilayah Kerja Puskesmas Pattingalloang

Berdasarkan hasil penelitian menunjukkan bahwa dari 56 Responden yang diteliti, diketahui bahwa hasil output uji normalitas Kolmogorov-Smirnov ${ }^{z}$ diperoleh nilai $\rho$ untuk pengetahuan pre test dan post test adalah 0,001 dimana nilai $\rho$ ini lebih kecil atau sama dengan dari pada nilai $\alpha=0,05$. Berdasarkan tingkat kemaknaan $\rho<\alpha(0,05)$, maka dapat disimpulkan bahwa data tersebut tidak berdistribusi normal, sehingga untuk mengetahui ada tidaknya perbedaan pengetahuan ibu sebelum dan sesudah diberikan media berbasis video digunakan uji statistic non-parametrik yaitu uji Wilcoxon Signed-Rank Test. Hasil penelitian tentang Pengaruh Media Berbasis Video Terhadap Pengetahuan Ibu Akseptor KB Tentang Pentingnya KB Di Wilayah Kerja Puskesmas Pattingalloang diperoleh interpretasi output ranks pada uji Wilcoxon Signed-Rang Test terdapat 0 responden yang mengalami penurunan pengetahuan, 56 responden mengalami peningkatan pengetahuan, dan 0 responden yang tidak mengalami perubahan pengetahuan. Berdasarkan hasil output SPSS signifikansi nilai rata-rata pre test 22,91 dan rata-rata post test 27,96 dengan nilai $\rho$ adalah 0,001 . Berdasarkan tingkat kemaknaan $\rho<\alpha(0,05)$, sehingga dapat disimpulkan bahwa ada Pengaruh Media Berbasis Video Terhadap Pengetahuan lbu Akseptor KB Tentang Pentingnya KB Di Wilayah Kerja Puskesmas Pattingalloang.

Hasil penelitian ini juga sejalan dengan penelitian yang dilakukan oleh Cynthia (2017) terdapat Pengaruh Pendidikan Kesehatan Melalui Media Video Terhadap Pengetahuan Ibu Primigravida Tentang Kontrasepsi IUD Post Plasenta Di Puskesmas Piyungan yang signifikan. Nilai $\rho$ (value) sebesar $0,000<\alpha=0.05$, sehingga dapat disimpulkan ada pengaruh pendidikan kesehatan melalui media video terhadap pengetahuan ibu primigravida tentang kontrasepsi IUD post plasenta di Puskesmas Piyungan. 
Penelitian ini sejalan dengan penelitian yang dilakukan Fuad \& Cristin (2017) yang menyatakan bahwa ada pengaruh yang signifikan terhadap pendidikan kesehatan tentang bahaya NAPZA melalui media video terhadap perubahan pengetahuan remaja kelas $X$ di MAN Maguwohardjo, Yogyakarta. Penelitian ini juga sejalan dengan penelitian yang dilakukan Imran (2017) yang menyatakan bahwa terdapat pengaruh yang signifikan tingkat pengetahuan dampak abortus provokatus kriminalis sebelum dan sesudah diberikan penyuluhan kesehatan melalui media video di kelas X SMAN 2 Gowa.

Menurut asumsi peneliti bahwa benar adanya peningkatan suatu pengetahuan sebelum dan sesudah diberikan media berbasis video secara signifikan. Kemudian dari hasil observasi dan wawancara terhadap beberapa responden diketahui bahwa pendidikan, pengalaman, status ekonomi serta kepercayaan yang masih begitu kental dan melekat di masyarakat yang menyebabkan beberapa responden takut serta berfikir kembali untuk memakai KB.

Dari semua jenis alat kontrasepsi, peneliti paling menganjurkan untuk menggunakan jenis alat kontrasepsi AKDR/IUD dikarenakan peneliti beranggapan bahwa dengan sekali pemasangan AKDR/IUD dapat bertahan dalam jangka waktu yang panjang tanpa ada lagi istilah lupa minum obat, jadwal

\section{DAFTAR PUSTAKA}

Ardina, C. V., \& Suratini. (2017). Pengaruh Pendidikan Kesehatan Melalui Media Video Terhadap Pengetahuan Ibu Primigravida Tentang Kontrasepsi lud Post Plasenta Di Puskesmas Piyungan. Jurnal Unisa, 1-9.

Farahan, N. (2016). Gambaran Tingkat Pengetahuan Penggunaan Alat Kontrasepsi Pada Wanita Usia Subur Dan Dukungan Petugas Di Desa Bebandem Kabupaten Karangasem Bali Tahun 2014. E-Jurnal Medika, 5(4), 1-12.

Fuad, S., \& Cristin, W. (2017). Pengaruh Pendidikan Kesehatan Melalui Media Video Terhadappengetahuan Bahaya Napza Pada Remaja Kelas X Man Maguwoharjo Yogyakarta. 4(April), 212-216.

Hidayatulloh, R. (2017). Pengaruh pendidikan kesehatan terhadap pengetahuan ibu-ibu tentang kb iud di dusun plosorejo desa jagir kecamatan sine kabupaten ngawi.

Imran, F. A. (2017). Pengaruh Penyuluhan Kesehatan Melalui Media Video Terhadap Peningkatan Pengetahuan Remaja Putri Tentang Dampak Abortus Provokatus Kriminalis Di Kelas X Sman 2 Gowa.

Kemenkes RI. (2014). Infodatin-Kb.Pdf. Info Datin, pp. 1-6.

Kemenkes RI. (2017). Profil Kesehatan Indonesia Tahun 2016.

Rizali, M. I., Ikhsan, M., \& Salmah, A. U. (2013). Faktor Yang Berhubungan Dengan Pemilihan Metode Kontrasepsi Suntik Di Kelurahan Mattoangin Kecamatan Mariso Kota Makassar. 176-183.

World Healt Organisation. (2018). WHO | Family Planning/Contraception. https://www.who.int/en/news-room/factsheets/detail/family-planning-contraception 